Originally published as:

Gültner, S., Kuhlmann, T., Hesse, A., Weber, J.P., Riemer, C., Baier, M., Hutloff, A.

Reduced treg frequency in LFA-1-deficient mice allows enhanced T effector differentiation and pathology in EAE

(2010) European Journal of Immunology, 40 (12), pp. 3403-3412.

DOI: 10.1002/eji.201040576

This is an author manuscript.

The definitive version is available at: http://onlinelibrary.wiley.com/ 


\title{
Reduced Treg frequency in LFA-1 deficient mice allows enhanced T effector differentiation and pathology in EAE
}

\author{
Sandra Gültner ${ }^{1}$, Tanja Kuhlmann ${ }^{2}$, Amke Hesse ${ }^{2}$, Jan P. Weber ${ }^{1,3}$, Constanze Riemer ${ }^{1}$, \\ Michael Baier ${ }^{1, *}$, Andreas Hutloff ${ }^{1,3, *}$
}

Affiliations:

${ }^{1}$ Robert Koch Institute, Nordufer 20, 13353 Berlin, Germany

${ }^{2}$ Institute of Neuropathology, University Hospital Muenster, Domagkstr. 19, 48149 Muenster, Germany

${ }^{3}$ German Rheumatism Research Centre Berlin (DRFZ), a Leibniz Institute, Charitéplatz 1 , 10117 Berlin, Germany

* Both senior authors contributed equally to this work

Key words: Autoimmunity, Neuroimmunology, Regulatory T cells

Correspondence: Andreas Hutloff, German Rheumatism Research Centre Berlin, Charitéplatz 1, 10117 Berlin, Germany; phone: +49-30-28460-792, fax: +49-30-28460-603, e-mail: Hutloff@drfz.de Abbreviations: MOG: myelin oligodendrocyte glycoprotein; LFB: Luxol Fast Blue; PAS: periodic acid-Schiff; PFA: paraformaldehyde 


\section{Summary}

The $\alpha$ Lß2-integrin LFA-1 (CD11a/CD18) is known as an important molecule for leukocyte migration. However, the precise role of LFA-1 in the pathogenesis of experimental autoimmune encephalomyelitis has so far remained unclear. We describe here the disease development in LFA-1 ${ }^{-/-}$mice compared to wild-type controls. Ablation of LFA-1 resulted in more severe EAE with increased demyelination and increased numbers of MOG-reactive CD4 ${ }^{+} \mathrm{T}$ cells in the CNS. However, the production of the pro-inflammatory cytokines IL-17 and IFN- $\gamma$ was unchanged on the level of antigen-specific T cells. Interestingly, LFA-1-deficient mice showed a clearly reduced frequency of regulatory T cells in the inflamed CNS. Moreover, Treg counts in spleens and thymi of unimmunized LFA-1 ${ }^{-/-}$mice were lower in comparison to the wild-type controls indicating an impairment of Treg generation. In combination, these results suggest a substantial role of LFA-1 in Treg generation and subsequent expansion of effector $\mathrm{T}$ cells and highlight the importance of Tregs in limiting EAE. 


\section{Introduction}

Experimental autoimmune encephalomyelitis (EAE) is a T cell-mediated inflammatory disease of the CNS and serves as an animal model for multiple sclerosis. The autoimmune phenotype can be induced in rodents sensitized to proteins like myelin basic protein or myelin oligodendrocyte glycoprotein (MOG). The disease is initiated by infiltration of peripheral lymphocytes and macrophages into the CNS and is characterized by local inflammation and demyelination. The migration of leukocytes into the CNS is facilitated by interactions of cell surface adhesion molecules and their endothelial ligands [1]. The family of $\beta 2$-integrins is involved in leukocytevascular cell interactions as well as in the communication between T cells and antigen presenting cells. The $\alpha \mathrm{L} \beta 2$-integrin LFA-1 (CD11a/CD18) is widely expressed by leukocytes including peripheral blood lymphocytes, monocytes, and NK cells [2]. Amongst the members of the $\beta 2$ family of integrins only LFA- 1 is expressed by CD4 ${ }^{+} \mathrm{T}$ cells and $\mathrm{CD} 4^{+} \mathrm{CD} 25^{+}$regulatory T cells (Treg) [3]. Interestingly, CD18-deficient mice, which do not express $\beta 2$-integrins, showed an impaired development of thymic and peripheral Treg cells but it remained unclear, which of the $\beta 2$-integrins is responsible for this phenotype [3].

The function of LFA-1 in EAE has been extensively studied. However, in part controversial and conflicting results have been obtained. E.g. treatment with anti-LFA-1 antibodies led to either protection against EAE [4] or to more severe disease development [5]. More recently, a deficiency for LFA-1 was suggested to dampen EAE upon active induction of an autoimmune response [6]. On the other hand, adoptive transfer of wild-type encephalitogenic T cells into LFA-1 ${ }^{-/-}$mice profoundly exacerbated the EAE course in comparison to wild-type mice indicating an anti-inflammatory role of LFA-1, which would limit disease progression [7]. It remained however elusive how LFA-1 exerts its immunosuppressive effects. To gain more insight into 
LFA-1 functions we further characterized LFA-1 ${ }^{-/-}$mice in comparison to wild-type controls in an EAE model. Taken together, we report here that the absence of LFA-1 promotes more severe EAE with increased demyelination and increased numbers of inflammatory cells migrating into the CNS. Moreover, we demonstrate that the loss of LFA-1 led to impaired generation of Treg cells, which in turn explains the observed overshooting autoimmune response against the MOG antigen. 


\section{Results}

\section{LFA-1 ${ }^{-/-}$mice develop more severe EAE}

To examine the role of LFA-1 in EAE induction we used a standard mouse model based on the subcutaneous immunization of $\mathrm{C} 57 \mathrm{BL} / 6$ mice with $\mathrm{MOG}_{35-55}$ peptide emulsified in complete Freund's adjuvant (CFA). The experiment was performed with wild-type $\left(\mathrm{LFA}-1^{+/+}\right), \mathrm{LFA}-1$ deficient $\left(\mathrm{LFA}-1^{-/-}\right)$, and heterozygous mice $\left(\mathrm{LFA}-1^{+/-}\right)$as an additional control. $\mathrm{LFA}-1^{+/-}$mice express LFA-1 at an intermediate level (data not shown). All experiments were performed with littermates to exclude any effects of different C57BL/6 substrains.

Wild-type mice typically developed first clinical signs of EAE between day 10 and 15 and reached the peak of disease between day 18 and 23. Clinical signs persisted on the peak level for at least 5-7 days before they slowly decreased. Interestingly, LFA-1 knock-out animals developed dramatically aggravated clinical signs and reached significantly higher clinical scores over the whole observation period (mean cumulative disease score until day 29: 31.4 vs. 14.7, $p<0.0001$, calculated across 3 independent experiments with $n=28$ or $n=27$ animals per group). A typical experiment is shown in Figure 1 and Table I. In addition, the incidence of EAE through day 21 was clearly higher, with $97.5 \%(+/-5.6)$ diseased LFA-1/- compared to $69.8 \%(+/-6.8)$ LFA $-1^{+/+}$animals (incidence $+/-$SEM, calculated from 6 independent experiments with $n=7$ to 15 animals per group). In terms of clinical signs $\mathrm{LFA}-1^{+/-}$mice behaved similar to the wild-type mice indicating that the intermediate expression of LFA-1 in these mice is sufficient for the biological function.

EAE pathology is mainly caused by the infiltration of inflammatory cells into the CNS tissue. This local inflammation subsequently leads to demyelination and axonal damage. We therefore 
analyzed the spinal cord of diseased mice for typical signs of inflammation and demyelination by histology (Fig. 2). At the peak of the disease significantly more perivascular infiltrates per spinal cord cross section were found in LFA- $1^{-/-}$mice compared to LFA-1 ${ }^{+/+}\left(\right.$LFA-1 ${ }^{-/-}: 4.4$ +/- 1.0; LFA- $\left.{ }^{+/+}: 1.16+/-0.28 ; p=0.024\right)$. Similarly, the extent of demyelination was significantly more prominent in $\mathrm{LFA}^{-1^{--}}(9.31 \%+/-1.9)$, whereas in $\mathrm{LFA}-1^{+/+}$almost no demyelination was observed $(0.76 \%+/-0.48 ; p=0.004)$. Moreover, in 3 out of 5 LFA- $1^{-/-}$mice prominent inflammatory infiltrates were detected in cerebellum and/or brain, whereas in the LFA- $1^{+/+}$mice only sparse inflammatory infiltrates in the cerebellum and/or brain were found (Fig. 2B). In the chronic disease phase (day 50 after immunization) the number of inflammatory infiltrates per spinal cord cross section was almost unchanged in both animal groups compared to the peak of disease (data not shown). Demyelination was still obvious in LFA-1 ${ }^{-/-}$mice $(4.57 \%+/-1.73)$ but almost completely absent in LFA- $1^{+/+}$mice $(0.12 \%+/-0.33)$.

\section{Enhanced generation of MOG-specific CD4 ${ }^{+} \mathrm{T}$ cells in LFA-1/-- mice}

To further analyze the cellular composition of the infiltrates we prepared single cell suspensions from spinal cords by mechanical disruption and enzymatic digestion with collagenase. As expected, the total number of cells obtained from spinal cords of LFA-1 ${ }^{-/}$mice was much higher compared to $\mathrm{LFA}-1^{+/+}$mice (Fig. 3A). To get more information about the composition of the infiltrates we used cell subset specific markers in flow cytometry. Next to microglia, $\mathrm{CD} 4^{+} \mathrm{T}$ cells represented the major leukocytic population in the spinal cord. Additionally, we found B cells, very few $\mathrm{CD}^{+}$T cells, NK cells, NK T cells, $ү \delta$ T cells, conventional dendritic cells, and plasmacytoid dendritic cells. All these latter populations did not differ significantly between $\mathrm{LFA}-1^{-/-}$and $\mathrm{LFA}-1^{+/+}$mice. 
Autoantigen-specific $\mathrm{CD}^{+} \mathrm{T}$ cells are known to be the major pathogenic factor in EAE [8]. To get information not only about total but MOG-specific $\mathrm{CD}^{+} \mathrm{T}$ cells we used a recently established system to detect antigen-specific T cells with high sensitivity [9]. The method is based on a short-term in vitro restimulation with the cognate antigen and subsequent staining for CD40L (CD154). This assay revealed that up to $50 \%$ of the infiltrating $\mathrm{CD} 4^{+} \mathrm{T}$ cells were specific for the autoantigen. Importantly, the frequency of MOG-specific CD4 ${ }^{+} \mathrm{T}$ cells was approximately twofold higher in $\mathrm{LFA}-1^{-/-}$compared to $\mathrm{LFA}-1^{+/+}$mice (Figure $3 \mathrm{~A}$ ). In combination with the higher absolute cell numbers this results in an about fivefold increased number of autoreactive T cells in the spinal cord of LFA-1 KO mice, which can easily explain the more aggravated disease. The frequency of autoreactive T cells directly correlated with disease severity $(r=0.82, p=0.0003$ for the experiment shown in Figure 3).

It is important to note that the higher cell number cannot be explained by different kinetics of lymphocyte infiltration because comparable results were obtained regardless whether both groups were analyzed at the same time point (which was not necessarily the peak of clinical signs for both groups) or the peak of the clinical score for individual animals.

As LFA-1 was shown to be involved in lymphocyte migration [10-11] it is tempting to speculate that the higher number of MOG-specific T cells in the spinal cord of LFA-1 knock-out mice is the result of an enhanced recruitment to the site of inflammation. However, when we used the same strategy to identify MOG-specific T cells in secondary lymphoid organs, it turned out that the difference in antigen-specific T cells was already established in the spleen and the draining lymph nodes (Figure 3B). Therefore, LFA-1 seems to control the generation and not the distribution of antigen-specific T cells. 


\section{The production of pro-inflammatory cytokines is not altered on the level of antigen- specific T cells}

Pro-inflammatory cytokines, namely IL-17 and IFN-Y, are well recognized as a major pathogenic factor in EAE [8]. As a recent report claimed that LFA-1 critically regulates the development of Th17 cells in EAE [6] we analyzed cytokine production by autoreactive $\mathrm{CD}^{+} \mathrm{T}^{\mathrm{T}}$ cells from diseased LFA- $1^{-/-}$and LFA- $1^{+/+}$mice. Cells from spinal cord were restimulated in vitro with MOGpeptide and stained intracellularly for IL-17 and IFN-y. As shown in Figure 4, MOG-specific T cells from inflamed spinal cords belonged to Th1, Th17, and Th17/Th1 subsets. However, the percentage of $\mathrm{CD} 4^{+} \mathrm{T}$ cells from $\mathrm{LFA}-1^{+/+}$and $\mathrm{LFA}-1^{-/-}$mice producing these cytokines was absolutely comparable on the level of antigen-specific cells. Also the amount of cytokines produced did not differ (MFI for IL-17: $20020+/-1457\left(\right.$ LFA- $\left.1^{+/+}\right)$vs. $21460+/-1080\left(\right.$ LFA- $\left.1^{-/-}\right), p=$

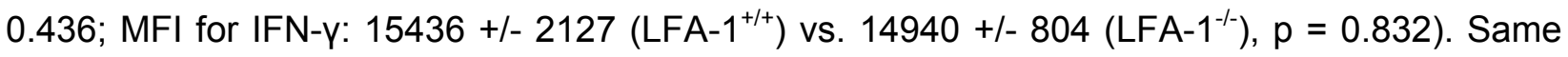
results were obtained for IL-2 and TNF- $\alpha$. However, it is important to note that the increased total number of antigen-specific cells finally results in a higher absolute number of cytokineproducing $\mathrm{CD}^{+} \mathrm{T}$ cells. Interestingly, there was also no correlation between EAE score of an individual animal and cytokine production on the single cell level. Again, only the number of infiltrating $\mathrm{CD}^{+}$cells correlates with disease severity (see above).

Polyfunctional Th1 cells producing multiple effector cytokines at the same time are thought to be particularly destructive in inflammation [12]. Therefore, we also analyzed whether the frequency of IL-2, IL-17, IFN-y double or triple producers was altered between wild-type and knock-out mice, but did not find any significant differences (data not shown). Alternatively, a change in Th2 or anti-inflammatory cytokines could influence the severity of disease. Therefore, we tested for production of IL-4 and IL-10. Only very few $(<2 \%)$ antigen-specific CD $4^{+} \mathrm{T}$ cells in the spinal 
cord produced these two cytokines. However, we did not observe any significant differences between LFA-1 $1^{+/+}$and LFA-1 ${ }^{-/-}$T cells (data not shown).

To analyze the general capacity of T cells to produce certain cytokines we additionally used an antigen-independent stimulation with PMA and ionomycin. Also with this kind of stimulation none of the analyzed cytokines differed between knock-out and wild-type mice (data not shown).

Taken together, these results clearly show that loss of LFA-1 does not alter the cytokine pattern of autoreactive $\mathrm{CD} 4^{+} \mathrm{T}$ cells. Therefore, only the increased total number of antigen-specific, cytokine-producing cells in LFA-1 ${ }^{-/-}$mice can be accounted for the increased severity of EAE.

\section{Decreased number of regulatory $\mathrm{T}$ cells in LFA-1/- mice}

Regulatory T cells play an important role for the suppression of chronic inflammation $[8,13]$. They control the expansion as well as function of autoreactive effector T cells. Utilizing intracellular staining for the lineage-specific transcription factor FoxP3 we analyzed Tregs in the spinal cord of LFA-1 $1^{-/-}$and LFA-1 ${ }^{+/+}$mice after EAE induction. The absolute number of Tregs was the same in both groups (Fig. 5). However, the higher number of MOG-reactive T cells in the spinal cord of LFA-1 ${ }^{-/-}$mice (Fig. 3A) drastically decreased the ratio of regulatory and effector T cells.

To see whether these relative differences in Tregs were the result of MOG-immunization or already established in the steady state, we analyzed Tregs in the spleen of non-immunized $\mathrm{LFA}_{-1} 1^{+/+}$and $\mathrm{LFA}-1^{-/-}$mice. While around $14 \%$ of $\mathrm{CD} 4^{+} \mathrm{T}$ cells in wild-type mice were FoxP3positive only approximately $5.5 \%$ regulatory T cells were found in LFA-1 knock-out mice (Fig. 6A). In contrast to the situation in the spinal cord, also absolute numbers of Tregs were 
diminished whereas numbers of CD44 ${ }^{\text {high }} \mathrm{CD} 2 \mathrm{~L}^{\text {low }}$ effector-memory phenotype $\mathrm{T}$ cells were unaltered in steady state (Fig. 6A). To get more information about the phenotype of Tregs in LFA-1 KO mice we analysed several markers defining subsets or which are known to be important for the function of Tregs, such as CTLA-4, GITR, OX40, and 4-1BB (supplementary Fig. S1). However, we could not find any differences.

Generally, a diminished population of Tregs can be explained by either reduced generation in the thymus or altered survival and homeostasis in the periphery. To discriminate these two possibilities we directly examined Tregs in the thymus of LFA- $1^{-/-}$and LFA-1 ${ }^{+/+}$mice. As reported earlier [14], there were neither obvious differences in size and cellularity of the thymus nor in the distribution of CD4/CD8 thymic subsets (Figure 6B and data not shown). Also histologically the thymus did not display any abnormalities. However, when we analyzed the frequency of FoxP $3^{+}$ $T$ cells in the different thymic subsets we found a significant reduction of Tregs in the CD4 ${ }^{+}$ single-positive subset of LFA-1/-- mice (Fig. 6B).

Taken together, our results clearly show that a reduced generation of naturally occurring Tregs in the thymus of LFA-1 knock-out mice results in a substantial lower frequency of Tregs in secondary lymphoid organs.

\section{Partial depletion of Tregs in WT mice resembles the phenotype of LFA-1 KO mice in EAE}

To test whether the reduced number of regulatory $\mathrm{T}$ cells in LFA-1 KO mice alone would be sufficient to explain the aggravated course of EAE we suboptimally depleted Tregs from WT mice. This was achieved by a single injection of the anti-CD25 mAb PC61. As shown in supplementary Fig. 2 this treatment resulted in a Treg frequency resembling LFA- $1^{-/-}$mice. WT mice, PC61-depleted WT mice, and LFA-1 KO mice were immunized with MOG-peptide. Fig. 7 
shows that the P61-depleted animals developed EAE scores absolutely comparable to LFA-1 ${ }^{-/-}$ mice. Interestingly, they even showed accelerated disease development. 


\section{Discussion}

Until now the exact role of LFA-1 in the pathogenesis of EAE is still elusive. There are several early studies using blocking monoclonal antibodies against LFA-1 which provided conflicting results. In one case this treatment resulted in a clear amelioration [4] while Welsh et al. [5] reported an augmentation of EAE. In a third study [15] the animals simply died from the injection of the antibody. However, since no $F\left(a b^{\prime}\right)_{2}$ fragments of the LFA-1 antibody were used it is unclear whether the observed effects were the result of a LFA-1 blockade, depletion of LFA-1 expressing cells, or signals via inhibitory Fc $\gamma$ receptors. Two more recent studies used LFA-1 knock-out mice. Wang et al. [6] observed a diminished EAE induction in LFA-1 ${ }^{-/-}$mice and attributed this to an impaired generation of Th17 cells. However, the authors neither analyzed antigen-specific T cells nor did they isolate T cells from the CNS. A further potential problem with this study may be due to the choice of control mice. LFA-1 KO mice were on a C57BL/6J background and bred in the authors' own facility whereas C57BL/6NCrl WT mice from a commercial breeder were used as control. In contrast, we used littermate LFA- $1^{--_{-}}$, LFA- $1^{+/-}$, and LFA $-1^{+/+}$mice, to avoid such ambiguities. In the second study, Dugger et al. [7] also reported diminished disease of LFA-1 KO mice in an active EAE model. However, in an adoptive transfer EAE model injection of wild-type encephalitogenic T cells into LFA-1 ${ }^{-/}$recipients resulted in a fatal EAE disease course. At that time the authors could not find an explanation for this different outcome. Our results now suggest that the reduced number of Tregs in the LFA- $1^{-/-}$recipients most likely resulted in enhanced expansion and activation of the transferred autoreactive $\mathrm{T}$ cells.

In our study ablation of LFA-1 results in an exacerbated disease in mice sensitized to a MOGderived peptide. We could correlate this augmented response to a defect in thymic Treg generation in LFA-1 knock-out mice. The reduced suppression by Tregs most likely leads to an 
enhanced generation of MOG-reactive T cells which then infiltrate the CNS. Interestingly, in this particular setting LFA-1 deficiency did not directly affect T cell effector function as determined by cytokine production on the single cell level. This is a quite unexpected finding given the reports showing that LFA-1 enhances T cell activation [16-17]. Obviously, in this specific EAE model the effect of LFA-1 on Treg generation is more dominant and determines the final biological outcome. We recently reported a similar finding for the inducible costimulator ICOS which augments the long-term survival of effector as well as regulatory T cells [18]. Dependent on the biological context, ICOS costimulation can result in pro-inflammatory as well as antiinflammatory effects. Now, LFA-1 seems to be another example of such a Janus-faced immune regulator.

Involvement of Tregs in the pathogenesis of EAE has been documented in numerous studies. Depletion of $\mathrm{CD}_{2} 5^{+}$cells in vivo usually resulted in an exacerbation of the disease whereas transfer of high numbers of regulatory T cells protected animals from EAE (reviewed in [13]). The general role of ß2-integrins for the development of Tregs have been first shown by Marski et al. [3] who observed a substantial reduction of Tregs in CD18 knock-out mice, which lack LFA-1 (CD11a/CD18), Mac-1 (CD11b/CD18), integrin $\alpha X$ (CD11c/CD18), and CD11d/CD18 at the same time. A very recent study reported reduced numbers of Tregs in secondary lymphoid organs of LFA-1 knock-out mice [19]. However, in contrast to our results they did not detect any differences in the thymus.

A number of studies suggested that Tregs exert their suppressive function on effector T cells indirectly by modifying the function of antigen-presenting dendritic cells. Interestingly, a recent in vitro study showed that LFA-1 is important for the formation of dendritic cell/Treg aggregates because LFA-1 ${ }^{-/-}$Tregs were no longer able to inhibit the maturation of cocultured dendritic cells 
[20]. Similar effects were also observed in a mixed human/mouse suppression system [21]. We show here that LFA-1 deficiency results in a reduced Treg/effector cell ratio in the inflamed CNS. The reduction in Tregs was already established in the spleen and thymi of unimmunized LFA-1 ${ }^{-/}$ mice. Hence, besides a possible functional impairment of Tregs lacking LFA-1 these results indicate a more fundamental role for LFA-1 in generation of FoxP3 ${ }^{+}$Tregs in the thymus. ICAM-1, a ligand of LFA-1, is expressed on thymic stromal cells [22]. Therefore, LFA-1 potentially increases the physical contact between thymocytes and stromal cells resulting in enhanced T cell receptor triggering. Increased T cell receptor signalling during thymocyte selection favours the generation of naturally occurring Tregs [23], which would explain the contribution of LFA-1 to the generation of naturally occurring Tregs.

So far, LFA-1 has been mainly recognized as a molecule regulating the migration of lymphocytes. Generally, the migration of LFA-1-deficient T cells to the peripheral lymph nodes is impaired, resulting in significantly smaller lymph nodes [10, 14]. However, upon immunization with MOG-peptide we observed that these differences in cellularity in lymph nodes between wildtype and LFA-1 knock-out mice is more or less levelled out (data not shown). In the context of EAE and transendothelial migration, Laschinger et al. [11] demonstrated that encephalitogenic T cells do not use LFA-1 for the initial adhesion to the endothelium of the blood/brain barrier. Instead, LFA-1 was involved in the later phases of migration into the CNS parenchyma. However, it should be noted that these results were obtained for the healthy spinal cord and that the role of LFA-1 for migration could be different during later stages of an EAE disease, in which other integrin interactions may compensate for the lack of LFA-1. In our study, we did not directly address the question of lymphocyte migration via the blood/brain barrier. However, the observation that the frequency of MOG reactive CD4+ T cells in LFA-1 ${ }^{-1-}$ mice is already higher outside the CNS suggests an impaired suppression of effector T cells by Tregs rather than an 
altered migration as cause for the higher ratio of effector versus regulatory $T$ cells in the inflamed CNS in LFA- $1^{-/-}$.

Overall, the exacerbated EAE in the absence of LFA-1 seems to be due to the impaired suppression of autoantigen-specific effector T cells by Tregs, which in LFA-1 ${ }^{-/-}$mice show a more extensive expansion in secondary lymphoid organs upon immunization with the MOGpeptide. Not surprisingly, this enhanced generation of autoreactive CD4 ${ }^{+} \mathrm{T}$ cells results in an increased infiltration of pathogenic MOG-specific T cells into the CNS and consequently in more severe demyelination and inflammation. In addition, our Treg depletion experiment shows that the reduced number of Tregs alone is sufficient to explain the aggravated EAE course. Therefore, additional functional defects of the Tregs appear to be unlikely but can, on the other hand, not totally be excluded. Taken together, our results point towards a crucial involvement for LFA-1 in Treg homeostasis and highlight the importance of Tregs in limiting EAE. Future work needs to determine, how Treg generation depends on the presence of LFA-1. 


\section{Materials and methods}

\section{Mice}

LFA-1-deficient mice [24] were obtained from the Jackson Laboratories and were backcrossed to $\mathrm{C} 57 \mathrm{BL} / 6$ for 13 generations. We further crossed them with C57BL/6 wild type mice and used littermates of LFA-1 ${ }^{+/}$inter-se matings for the experiments. Animal handling and experiments were conducted according to the German animal protection laws and approved by the responsible governmental authority.

\section{EAE induction}

For EAE induction, six to ten weeks old mice were anaesthetized with ketamine $(94 \mathrm{mg} / \mathrm{kg}$ body weight) and xylazine $(6.25 \mathrm{mg} / \mathrm{kg})$ and immunized subcutaneously at two sites of the back close to inguinal lymph nodes with $200 \mu \mathrm{g}$ myelin oligodendrocyte glycoprotein $35-55\left(\mathrm{MOG}_{35-55}\right)$ in CFA (EAE Induction Kit ${ }^{\mathrm{TM}}, \mathrm{MOG}_{35-55}$ /CFA Emulsion PTX (3.75x), Hooke Laboratories). Directly after immunization mice received a first dose of $400 \mathrm{ng}$ pertussis toxin intraperitoneally followed by a second injection the day after. After one week mice were scored daily for clinical signs according to the following scale: $0=$ no obvious changes in motor functions; $1=\operatorname{limp}$ tail; $2=$ limp tail and weakness of hind legs; $3=\operatorname{limp}$ tail and complete paralysis of hind legs; $4=\operatorname{limp}$ tail, complete hind leg and partial front leg paralysis; $5=$ complete hind and complete front leg paralysis.

\section{Depletion of regulatory $\mathrm{T}$ cells}

8 days prior induction of EAE mice were treated with $500 \mu \mathrm{g}$ anti-CD25 (clone PC61.5) i.p. The antibody preparation was controlled to contain less than $0.1 \mathrm{ng}$ endotoxin/mg of protein by limulus amoebocyte lysate assay. 


\section{Histology}

Mice were perfused under deep anaesthesia through the left cardiac ventricle with PBS followed by $4 \%$ paraformaldehyde (PFA). Brain and spinal cord were removed, post-fixed in PFA over night and embedded in paraffin. Five $\mu \mathrm{m}$ thick sections were stained for haematoxylin-eosin, Luxol Fast Blue (LFB) / periodic acid-Schiff (PAS), and Bielschowsky's silver impregnation. Immunohistochemistry was performed with an avidin-biotin technique. For immunohistochemistry sections were deparaffinised and intrinsic peroxidase activity was blocked by incubation with $5 \% \mathrm{H}_{2} \mathrm{O}_{2}$ in PBS for 20 min. Non-specific antibody binding was inhibited with 10\% FCS in PBS for 25 min. Macrophages/microglial cells were detected using an anti-Mac-3 antibody (BD Biosciences) with biotinylated anti-mouse Ig (GE Healthcare) as secondary reagent. Staining was developed using the avidin-biotin technique and 3,3'-diaminobenzidine as chromogen.

To quantify the demyelinated area transverse spinal cord cross sections from all regions of the spinal cord were analyzed (between five and eleven cross sections per animal). The demyelinated area was measured in sections stained for LFB/PAS, and expressed as percentage of total white matter. For statistical analysis the mean per animal was calculated. Similarly, the numbers of inflammatory infiltrates were counted in all transverse spinal cord sections and the mean per section was calculated.

\section{Cell preparation}

To prepare single cell suspensions from spleen, peripheral lymph nodes, or thymus organs were cut into small pieces and meshed through a sieve. For cell preparation from spinal cords mice were perfused with $25 \mathrm{ml}$ PBS via the left cardiac ventricle under deep anaesthesia. The spinal cord was removed and collected in cold medium (RPMI 1640, 0.5\% BSA). A single cell 
suspension was prepared using the gentleMACS dissociator (Miltenyi Biotec) and digestion with $0.5 \mathrm{mg} / \mathrm{ml}$ collagenase $\mathrm{D}$ and $20 \mu \mathrm{g} / \mathrm{ml}$ DNase I (both from Roche) for $30 \mathrm{~min}$ at $37^{\circ} \mathrm{C}$. To stop digestion $10 \mathrm{mmol}$ EDTA was added for the last $5 \mathrm{~min}$. To remove residual pieces of tissue the suspension was filtered through a $100 \mu \mathrm{m}$ filter. Cells were counted using a Guava PCA capillary flow cytometer and ViaCount solution (Millipore).

\section{Flow cytometry}

Single cell suspensions from spinal cord, lymph nodes, spleen, or thymus were suspended in staining buffer (PBS, 2.5\% FCS, 0.1\% $\mathrm{NaN}_{3}, 20 \mu \mathrm{g} / \mathrm{ml} 2.4 \mathrm{G} 2$ (anti-FcyRII/III)) and incubated on ice with different combinations of the following fluorophore-conjugated mAb: Pacific Blueconjugated KT3 (anti-CD3), PE- or PE-Cy7-conjugated GK1.5 (anti-CD4), Alexa Fluor 700conjugated 53-6.72 (anti-CD8), FITC- or PE-conjugated IM7.8.1 (anti-CD44), Pacific Orangeconjugated RA3-6B2 (anti-B220), FITC- or PE-Cy7-conjugated MEL-14 (anti-CD62L), Allophycocyanin-Cy7-conjugated 30-F11 (anti-CD45; BioLegend), Allophycocyanin-Alexa Fluor 750-conjugated 53-6.7 (anti-CD8; eBioscience), and PE-conjugated 17B5 (anti-4-1BB; eBioscience), Ox-86 (anti-OX40), DTA-1 (anti-GITR; eBioscience), UC10-4F10 (anti-CTLA-4), 2E4 (anti-CD25). Antibodies from non-commercial sources were purified from hybridoma supernatants and coupled to the respective fluorophore by standard procedures. For intracellular staining of FoxP3, Alexa Fluor 647-conjugated FJK-16s and a commercial buffer set (both from eBioscience) were used. Isotype controls were used to control specificity of staining. To discriminate dead cells, either DAPI was added to live cells immediately before analysis or cells were incubated on ice for $25 \mathrm{~min}$ with $0.67 \mathrm{mM}$ Pacific Orange succinimidyl ester (Invitrogen) prior to fixation (modified protocol from [25]). $1 \times 10^{5}$ to $2 \times 10^{6}$ cells were analyzed on a LSR II flow cytometer (405 nm, $488 \mathrm{~nm}$, and $633 \mathrm{~nm}$ excitation; BD Biosciences). Data were further analyzed with FlowJo Software (Treestar). Analysis gates were set on live cells defined by 
scatter characteristics and exclusion of DAPI or Pacific Orange positive cells. Doublets were excluded using FSC and SSC height vs. area characteristics.

\section{Analysis of antigen-specific cells and cytokine production}

For analysis of antigen-specific cells and cytokine production cells were suspended at $5 \times 10^{6}$ per $\mathrm{ml}$ in medium (RPMI 1640, 10\% FCS) and restimulated with $25 \mu \mathrm{g} / \mathrm{ml} \mathrm{MOG}_{35-55}$ (MoBiTec) for $6 \mathrm{~h}$ at $37^{\circ} \mathrm{C}$. After $2 \mathrm{~h}$ of culture, $5 \mu \mathrm{g} / \mathrm{ml}$ brefeldin A (Sigma) was added.

After staining of cell surface antigens and live/dead discrimination with Pacific Orange, cells were fixed with formaldehyde and permeabilised with saponin (buffer set from eBioscience). Unspecific binding sites were blocked with $100 \mu \mathrm{g} / \mathrm{ml} 2.4 \mathrm{G} 2$ and $50 \mu \mathrm{g} / \mathrm{ml}$ purified rat $\mathrm{lg}$ (Nordic) and cells were stained intracellularly with the following fluorophore-conjugated mAb: FITCconjugated TC11-18H10 (anti-IL-17) or MP6-XT22 (anti-TNF- $\alpha$ ), PE-conjugated MR1 (antiCD40L; all from BioLegend), digoxygenin-conjugated JES6-5H4 (anti-IL-2) or JES5-2A5 (antiIL-10), Pacific Blue conjugated AN18.17.24 (anti-IFN-y) or 11B11 (anti-CD4). As secondary reagent Alexa Fluor 647-conjugated anti-digoxygenin (Roche) was used. To determine the individual staining background of the anti-cytokine mAb a control sample was included where cells were preincubated with a 100-fold excess of unlabeled antibody (cold blocking control). Cells were further analyzed by flow cytometry as described above.

\section{Statistical analysis}

All data were analyzed using GraphPad Prism software using either Student's t test to determine differences between two groups, Kruskal-Wallis test for the scoring curves, or Pearson test for correlation of two parameters. Variation within experimental groups is reported as SEM. 
Acknowledgments: We would like to thank Sybill Lichy and Mari Wildhagen for help with the experiments, O. Aktas, U. Schulze Topphoff, and F. Zipp for their initial advice and help concerning the EAE procedure, and the whole animal facility. This work was supported by grant DFG HU $1294 / 3$ to A.H.

Conflict of interest: The authors declare no financial or commercial conflict of interest. 


\section{References}

1 Engelhardt, B., Molecular mechanisms involved in T cell migration across the blood-brain barrier. J Neural Transm 2006. 113: 477-485.

2 Lub, M., van Kooyk, Y. and Figdor, C. G., Ins and outs of LFA-1. Immunol Today 1995. 16: $479-483$.

3 Marski, M., Kandula, S., Turner, J. R. and Abraham, C., CD18 is required for optimal development and function of CD4+CD25+ T regulatory cells. J Immunol 2005. 175: 78897897.

4 Gordon, E. J., Myers, K. J., Dougherty, J. P., Rosen, H. and Ron, Y., Both anti-CD11a (LFA-1) and anti-CD11b (MAC-1) therapy delay the onset and diminish the severity of experimental autoimmune encephalomyelitis. J Neuroimmunol 1995. 62: 153-160.

5 Welsh, C. T., Rose, J. W., Hill, K. E. and Townsend, J. J., Augmentation of adoptively transferred experimental allergic encephalomyelitis by administration of a monoclonal antibody specific for LFA-1 alpha. J Neuroimmunol 1993. 43: 161-167.

6 Wang, Y., Kai, H., Chang, F., Shibata, K., Tahara-Hanaoka, S., Honda, S., Shibuya, A. and Shibuya, K., A critical role of LFA-1 in the development of Th17 cells and induction of experimental autoimmune encephalomyelytis. Biochem Biophys Res Commun 2007. 353: 857-862.

7 Dugger, K. J., Zinn, K. R., Weaver, C., Bullard, D. C. and Barnum, S. R., Effector and suppressor roles for LFA-1 during the development of experimental autoimmune encephalomyelitis. J Neuroimmunol 2009. 206: 22-27.

8 Korn, T., Anderson, A. C., Bettelli, E. and Oukka, M., The dynamics of effector T cells and Foxp3+ regulatory $\mathrm{T}$ cells in the promotion and regulation of autoimmune encephalomyelitis. J Neuroimmunol 2007. 191: 51-60.

9 Kirchhoff, D., Frentsch, M., Leclerk, P., Bumann, D., Rausch, S., Hartmann, S., Thiel, A. and Scheffold, A., Identification and isolation of murine antigen-reactive $T$ cells according to CD154 expression. Eur J Immunol 2007. 37: 2370-2377.

10 Berlin-Rufenach, C., Otto, F., Mathies, M., Westermann, J., Owen, M. J., Hamann, A. and Hogg, N., Lymphocyte migration in lymphocyte function-associated antigen (LFA)-1deficient mice. J Exp Med 1999. 189: 1467-1478.

11 Laschinger, M., Vajkoczy, P. and Engelhardt, B., Encephalitogenic T cells use LFA-1 for transendothelial migration but not during capture and initial adhesion strengthening in healthy spinal cord microvessels in vivo. Eur J Immunol 2002. 32: 3598-3606. 
12 Darrah, P. A., Patel, D. T., De Luca, P. M., Lindsay, R. W., Davey, D. F., Flynn, B. J., Hoff, S. T., Andersen, P., Reed, S. G., Morris, S. L., Roederer, M. and Seder, R. A., Multifunctional TH1 cells define a correlate of vaccine-mediated protection against Leishmania major. Nat Med 2007. 13: 843-850.

13 Bynoe, M. S., Bonorino, P. and Viret, C., Control of experimental autoimmune encephalomyelitis by CD4+ suppressor T cells: peripheral versus in situ immunoregulation. J Neuroimmunol 2007. 191: 61-69.

14 Schmits, R., Kundig, T. M., Baker, D. M., Shumaker, G., Simard, J. J., Duncan, G., Wakeham, A., Shahinian, A., van der Heiden, A., Bachmann, M. F., Ohashi, P. S., Mak, T. W. and Hickstein, D. D., LFA-1-deficient mice show normal CTL responses to virus but fail to reject immunogenic tumor. J Exp Med 1996. 183: 1415-1426.

15 Cannella, B., Cross, A. H. and Raine, C. S., Anti-adhesion molecule therapy in experimental autoimmune encephalomyelitis. J Neuroimmunol 1993. 46: 43-55.

16 Bachmann, M. F., McKall-Faienza, K., Schmits, R., Bouchard, D., Beach, J., Speiser, D. E., Mak, T. W. and Ohashi, P. S., Distinct roles for LFA-1 and CD28 during activation of naive T cells: adhesion versus costimulation. Immunity 1997. 7: 549-557.

17 Wang, Y., Shibuya, K., Yamashita, Y., Shirakawa, J., Shibata, K., Kai, H., Yokosuka, T., Saito, T., Honda, S., Tahara-Hanaoka, S. and Shibuya, A., LFA-1 decreases the antigen dose for T cell activation in vivo. Int Immunol 2008. 20: 1119-1127.

18 Burmeister, Y., Lischke, T., Dahler, A. C., Mages, H. W., Lam, K. P., Coyle, A. J., Kroczek, R. A. and Hutloff, A., ICOS controls the pool size of effector-memory and regulatory T cells. J Immunol 2008. 180: 774-782.

19 Wohler, J., Bullard, D., Schoeb, T. and Barnum, S., LFA-1 is critical for regulatory T cell homeostasis and function. Mol Immunol 2009. 46: 2424-2428.

20 Onishi, Y., Fehervari, Z., Yamaguchi, T. and Sakaguchi, S., Foxp3+ natural regulatory T cells preferentially form aggregates on dendritic cells in vitro and actively inhibit their maturation. Proc Natl Acad Sci U S A 2008. 105: 10113-10118.

21 Tran, D. Q., Glass, D. D., Uzel, G., Darnell, D. A., Spalding, C., Holland, S. M. and Shevach, E. M., Analysis of adhesion molecules, target cells, and role of IL-2 in human FOXP3+ regulatory T cell suppressor function. J Immunol 2009. 182: 2929-2938.

22 Lepesant, H., Reggio, H., Pierres, M. and Naquet, P., Mouse thymic epithelial cell lines interact with and select a CD3lowCD4+CD8+ thymocyte subset through an LFA-1dependent adhesion--de-adhesion mechanism. Int Immunol 1990. 2: 1021-1032. 
23 Sakaguchi, S., Yamaguchi, T., Nomura, T. and Ono, M., Regulatory T cells and immune tolerance. Cell 2008. 133: 775-787.

24 Ding, Z. M., Babensee, J. E., Simon, S. I., Lu, H., Perrard, J. L., Bullard, D. C., Dai, X. Y., Bromley, S. K., Dustin, M. L., Entman, M. L., Smith, C. W. and Ballantyne, C. M., Relative contribution of LFA-1 and Mac-1 to neutrophil adhesion and migration. $J$ Immunol 1999. 163: 5029-5038.

25 Perfetto, S. P., Chattopadhyay, P. K., Lamoreaux, L., Nguyen, R., Ambrozak, D., Koup, R. A. and Roederer, M., Amine reactive dyes: an effective tool to discriminate live and dead cells in polychromatic flow cytometry. J Immunol Methods 2006. 313: 199-208. 


\section{Figure Legends}

\section{Figure 1. Clinical course of EAE development.}

${\text { LFA }-1^{-/-}}_{(n=13)}, \mathrm{LFA}_{-1}^{+/+}(n=14)$, and LFA-1 ${ }^{+/-}(n=12)$ mice were immunized with CFA emulsified MOG-peptide subcutaneously. Animals were scored daily for clinical signs. Shown is the mean clinical score for each group $\left( \pm\right.$ SEM). $\mathrm{LFA}-1^{-/-}$mice developed significantly higher disease scores compared to $\mathrm{LFA}^{-1 /+}$ mice $(p=0.0053$, t-test; $\mathrm{p}=0.0035$, Kruskal-Wallis test). A representative experiment out of seven independent experiments is shown.

Figure 2. Histological analysis of spinal cord and brain inflammation and demyelination. Spinal cords and brains from $\mathrm{LFA}-1^{+/+}$and $\mathrm{LFA}-1^{-/-}$mice were removed at the peak of EAE disease for each group and embedded in paraffin. Transverse sections from all regions of the spinal cord and brain were stained with Luxol Fast Blue / periodic acid-Schiff reagent or Mac-3 immunohistochemistry (representative stainings are shown in B).

(A) To quantify inflammation the numbers of Mac-3 positive infiltrates were counted in all spinal cord sections and the mean per transverse section was calculated for each animal. In addition, the demyelinated area was measured and expressed as percentage of total white matter. Data were analyzed using Student's t test.

\section{Figure 3. Analysis of MOG-specific CD4 ${ }^{+} \mathrm{T}$ cells.}

(A) Analysis of lymphocyte infiltration in the spinal cord. At the peak of disease (day 21) spinal cords from LFA $-1^{+/+}$and LFA-1 $1^{-/-}$mice were removed and single cell suspensions prepared. The upper left panel shows total numbers of infiltrating cells per spinal cord (representative experiment out of four). For analysis of antigen-specific $\mathrm{CD}^{+} \mathrm{T}$ cells, total cells were stimulated in vitro with MOG-peptide for $6 \mathrm{~h}$ and stained for CD45, CD4, CD8, and intracellularly for CD40L and IFN-y. Typically, approximately $80 \%$ of isolated cells were CD45 ${ }^{\text {high }}$ in both groups. The 
representative flow cytometric staining shows that not only the overall frequency of $C D 4^{+} \mathrm{T}$ cells (gated on live CD45 $5^{\text {high }}$ cells) is higher in LFA-1-1- mice but also the frequency of antigen-specific T cells $\left(\mathrm{CD} 4 \mathrm{~L}^{+}\right)$within the $\mathrm{CD}^{+}$population. As the combined effect the two plots on the right show the total number of MOG-specific $\mathrm{CD}^{+} \mathrm{T}$ cells and their frequency of live CD45 high cells. Shown is a representative experiment out of two with $n=14$ animals in each group. (B) Analysis of antigen-specific $\mathrm{CD}^{+} \mathrm{T}$ cells from spleen and lymph nodes. Same animals and same strategy to identify MOG-specific CD4 ${ }^{+}$T cells as in panel A. Data were analyzed using Student's t test.

\section{Figure 4. Cytokine production by MOG-specific CD4 ${ }^{+} \mathrm{T}$ cells in the spinal cord.}

Cells from inflamed spinal cords (day 21) were stimulated in vitro with MOG-peptide for $6 \mathrm{~h}$ and stained for CD45, CD4, and intracellularly for CD40L, IFN-y, TNF-a, IL-2, and IL-17. The upper panel shows a representative flow cytometric analysis for the coexpression of IL-17 and IFN-y by live CD45 ${ }^{\text {high }} \mathrm{CD}^{+} \mathrm{CD} 40 \mathrm{~L}^{+} \mathrm{MOG}-$ specific T cells from a LFA- $1^{+/+}$and $\mathrm{LFA}-1^{-/-}$mouse. The lower panel shows IFN-y, IL-17, TNF- $\alpha$, and IL-2 expression by MOG-specific CD4 ${ }^{+} \mathrm{T}_{\text {cells }}$ for all animals from a representative experiment out of two. Data were analyzed using Student's $t$ test.

\section{Figure 5. Regulatory T cells in the spinal cord.}

Cells were prepared from spinal cords of $\mathrm{LFA}-1^{+/+}$and $\mathrm{LFA}-1^{-{ }^{-}}$mice at day 16 after EAE induction (peak of disease). To quantify Tregs by flow cytometry cells were stained for CD45, CD3, CD4, CD8, and intracellular FoxP3. Exemplary flow cytometric data (gated on live CD45 ${ }^{\text {high }}$ $\mathrm{CD}^{+} \mathrm{T}$ cells) and results for all animals from a representative experiment out of four are shown. Data were analyzed using Student's t test. 
Figure 6. Regulatory $\mathrm{T}$ cells in spleen and thymus.

Flow cytometric analysis of $(A)$ spleen and $(B)$ thymus from unimmunized LFA-1 ${ }^{+/+}$and LFA-1 ${ }^{-1-}$ mice. Cells were stained for CD45, CD3, CD4, CD8, and intracellular FoxP3 and analyzed by flow cytometry. Shown is the gating strategy to identify regulatory T cells. Graphs represent (A) the proportion of $\mathrm{FoxP}^{+}$cells within the $\mathrm{CD} 4^{+}$subset and their absolute number per spleen. In addition, the absolute numbers of effector-memory $\left(\mathrm{CD} 44^{\text {high }} C D 62 L^{\text {low }}\right)$ and naive $\left(\mathrm{CD} 44^{\text {high }} \mathrm{CD} \mathrm{L}^{\text {low }}\right) \mathrm{T}$ cells are shown $(\mathrm{B})$ the proportion of FoxP3 ${ }^{+}$cells within the subset of CD4 single-positive thymocytes. Representative results out of two independent experiments. Data were analyzed using Student's t test.

Figure 7. Clinical course of EAE with Treg-depleted mice.

LFA-1 $^{-1-}(n=7)$, LFA $^{-1 /+}(n=7)$, and Treg-depleted LFA-1 ${ }^{+/+}(n=7)$ mice were immunized with CFA emulsified MOG-peptide subcutaneously. Animals were scored daily for clinical signs. Shown is the mean clinical score for each group $\left( \pm\right.$ SEM). LFA-1 ${ }^{-1 /}$ and PC61-depleted mice developed significantly higher disease scores compared to LFA- ${ }^{+/+}$mice $(p=0.014$ and $p<0.0001$, respectively; Student's t test.

Table I. Clinical course of EAE. Additional information for the experiment shown in Fig. 1

\begin{tabular}{lccc}
\hline & LFA-1 $^{+/+}$ & LFA-1 $^{\text {+/- }}$ & LFA-1 $^{-/-}$ \\
\hline Disease incidence (d21) & $10 / 14$ & $9 / 12$ & $13 / 13$ \\
Disease incidence (d32) & $13 / 14$ & $9 / 12$ & $13 / 13$ \\
Mean cumulative score (until d32) & 20.8 & 18.3 & 35.6 \\
\hline
\end{tabular}




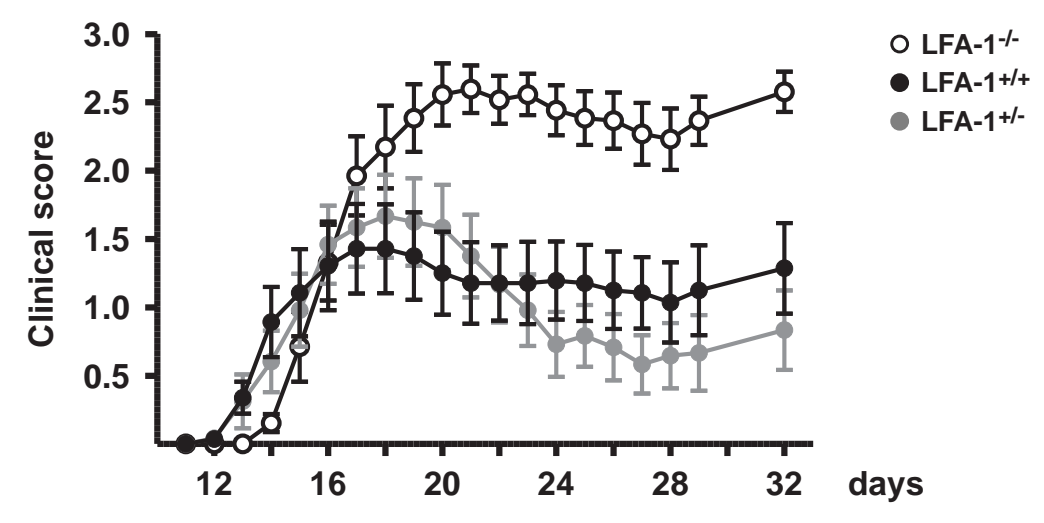

Fig. 1 
A
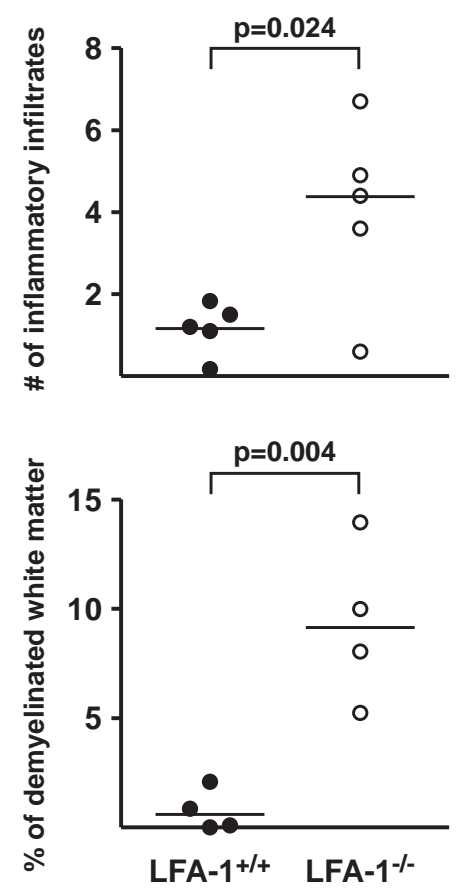

B
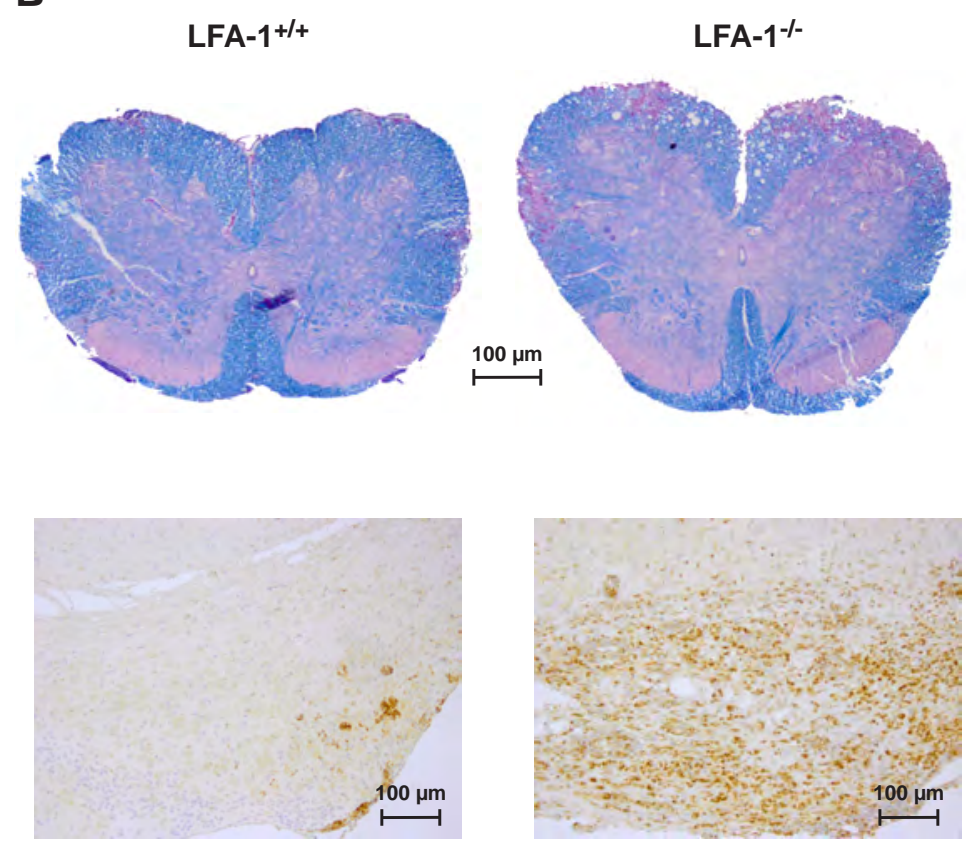

Fig. 2 
A
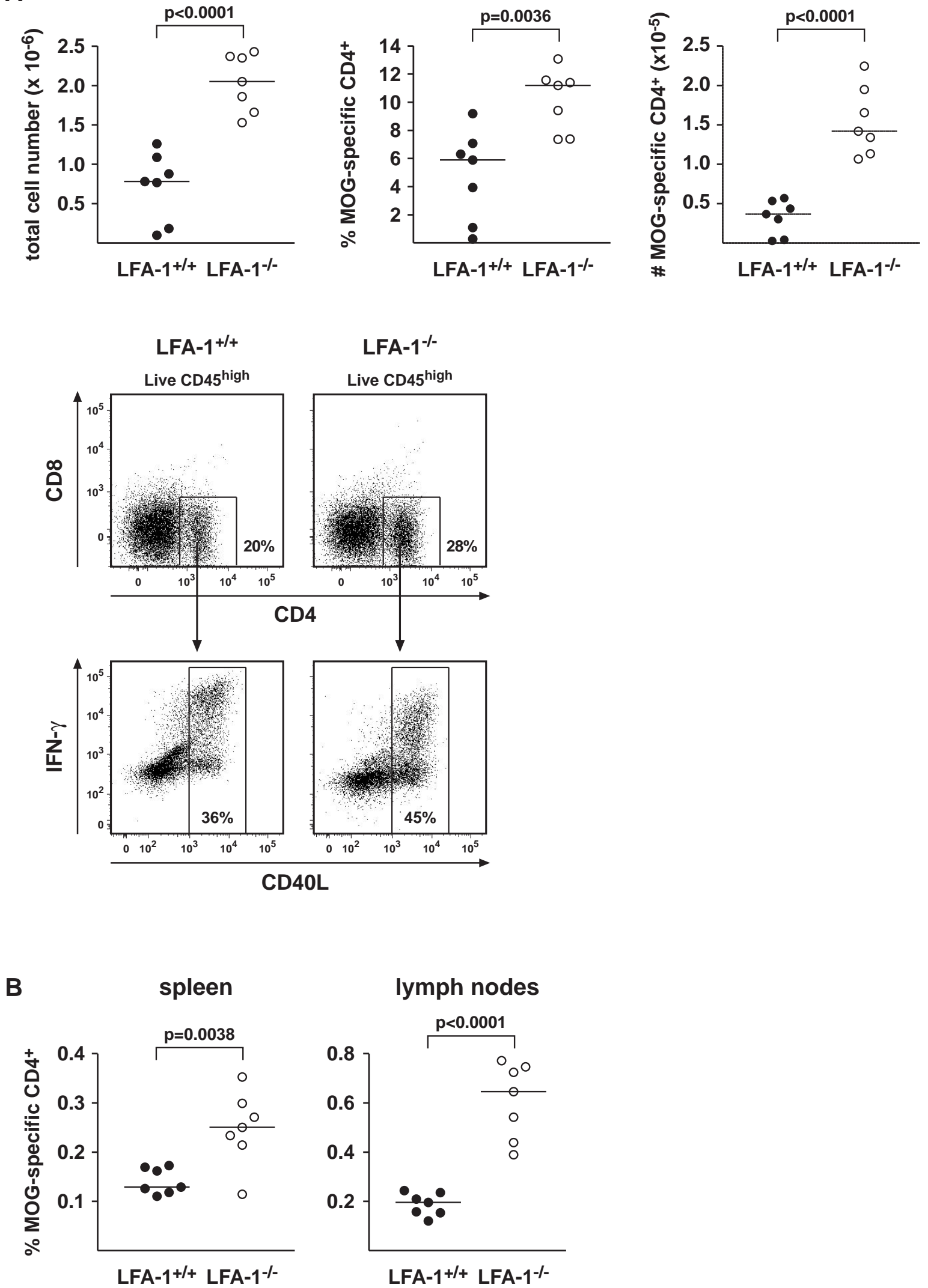

lymph nodes

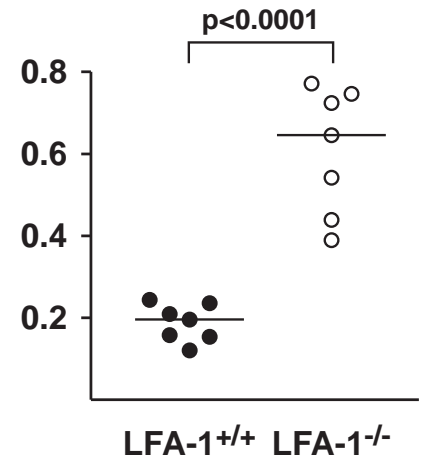

Fig. 3 
LFA- $1^{+/+} \quad$ LFA-1 ${ }^{-/-}$

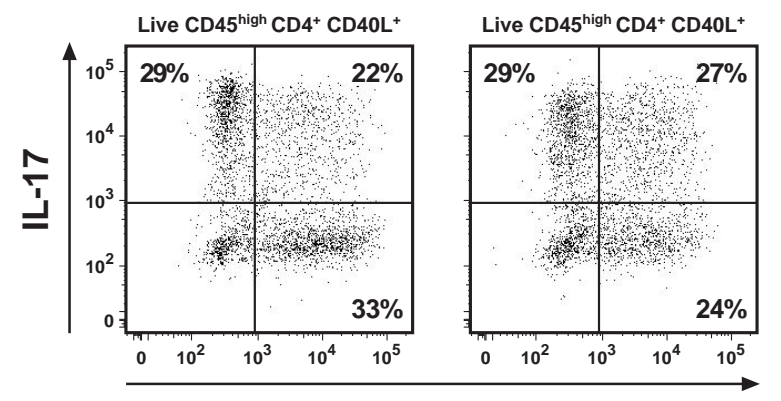

IFN- $\gamma$
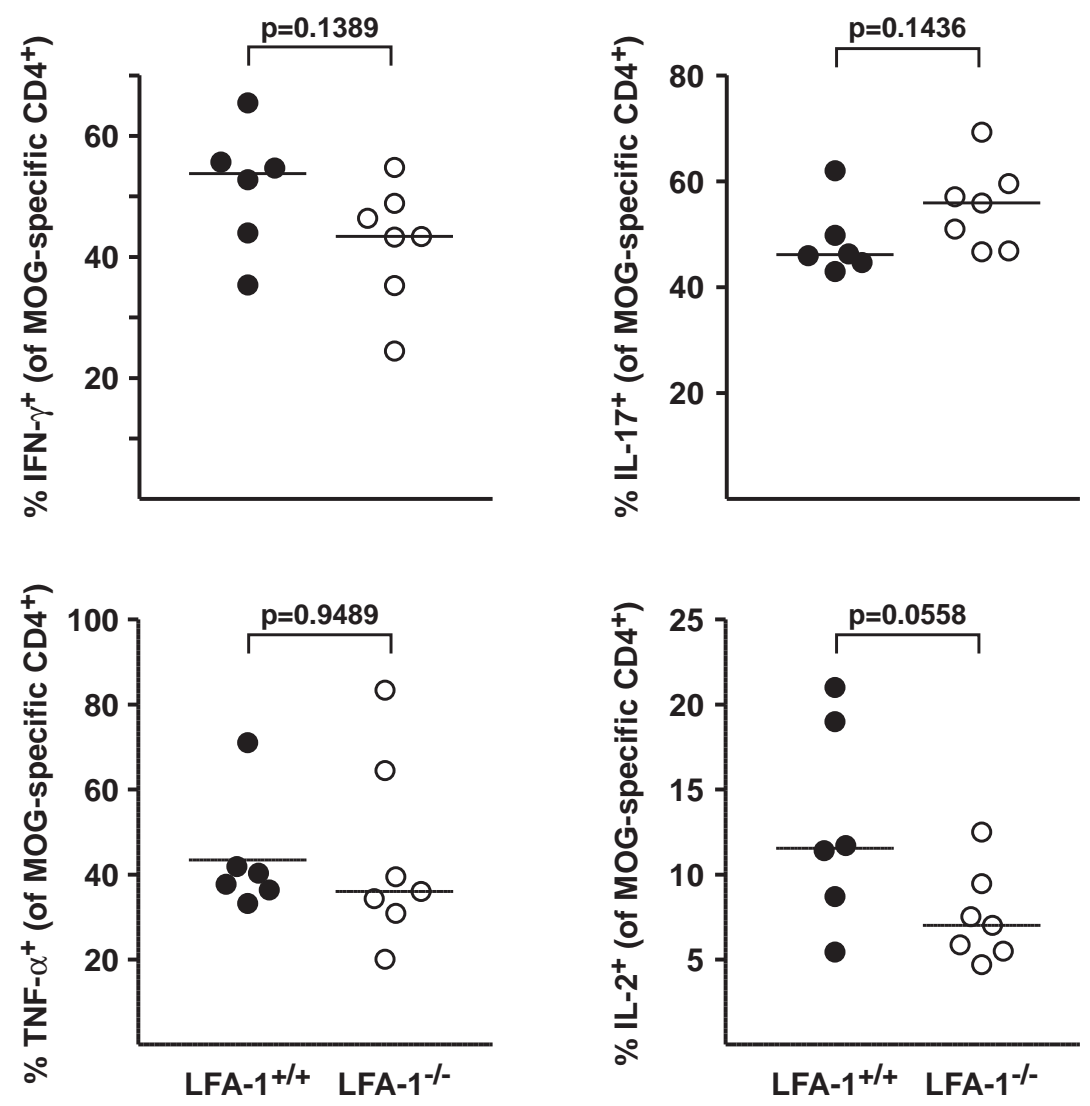

Fig. 4 


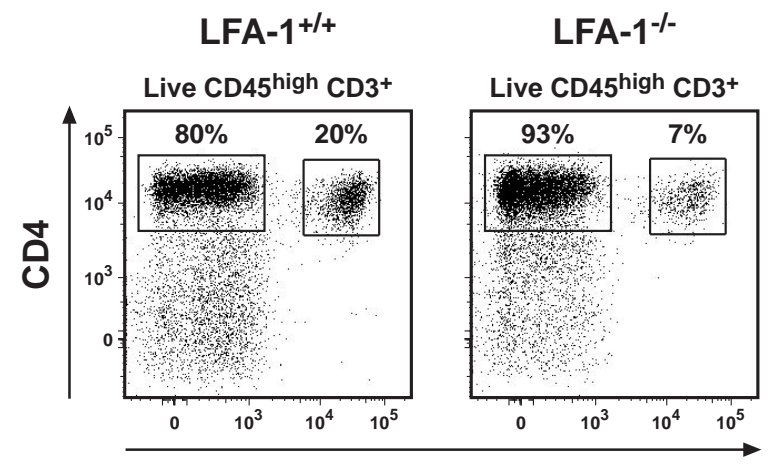

FoxP3
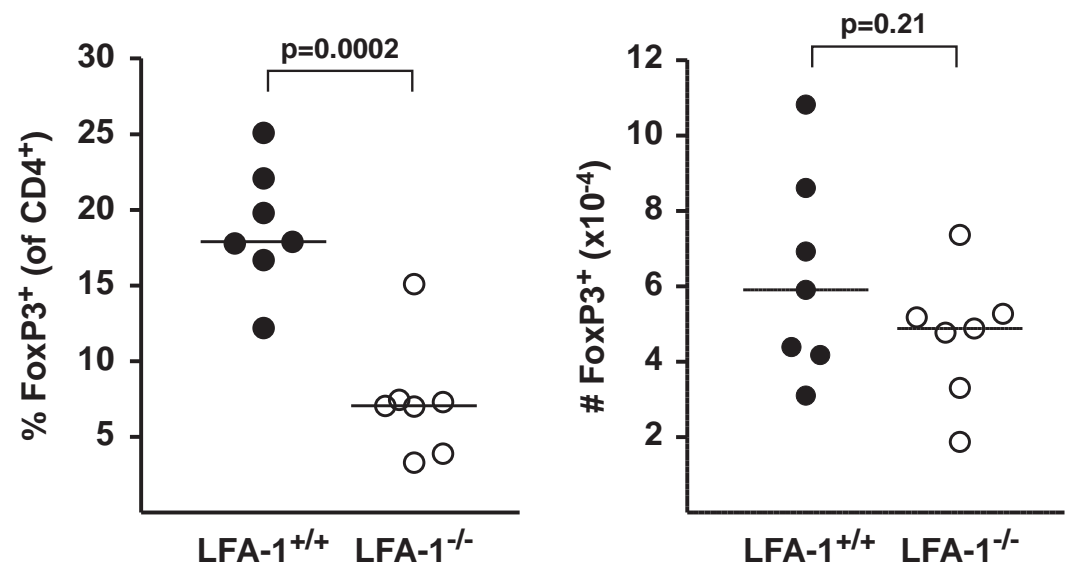

Fig. 5 
A
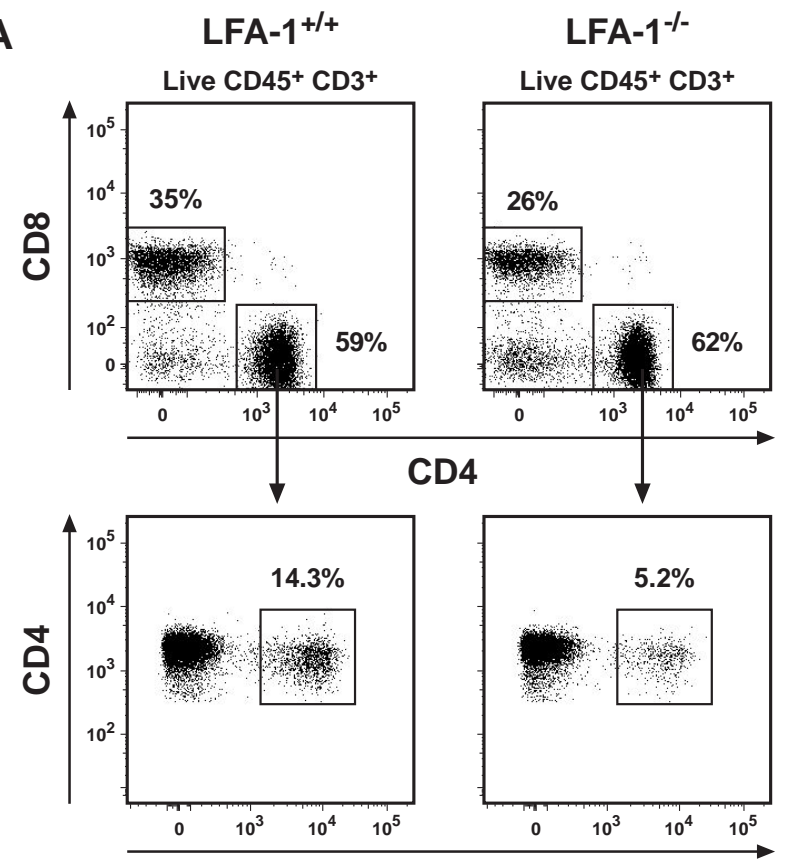

FoxP3

B

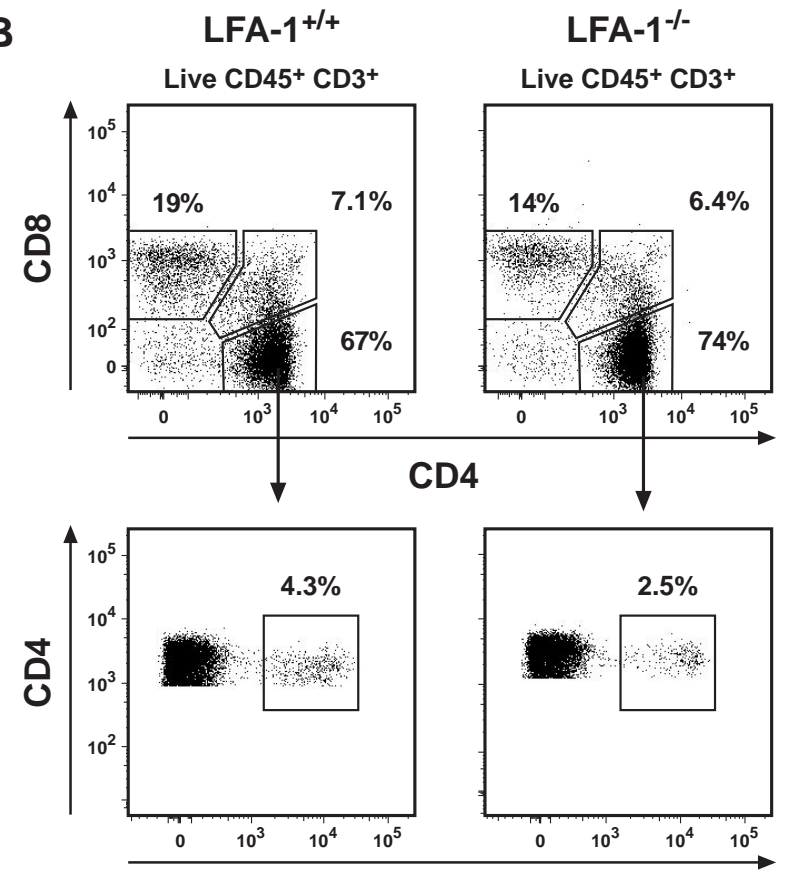

FoxP3
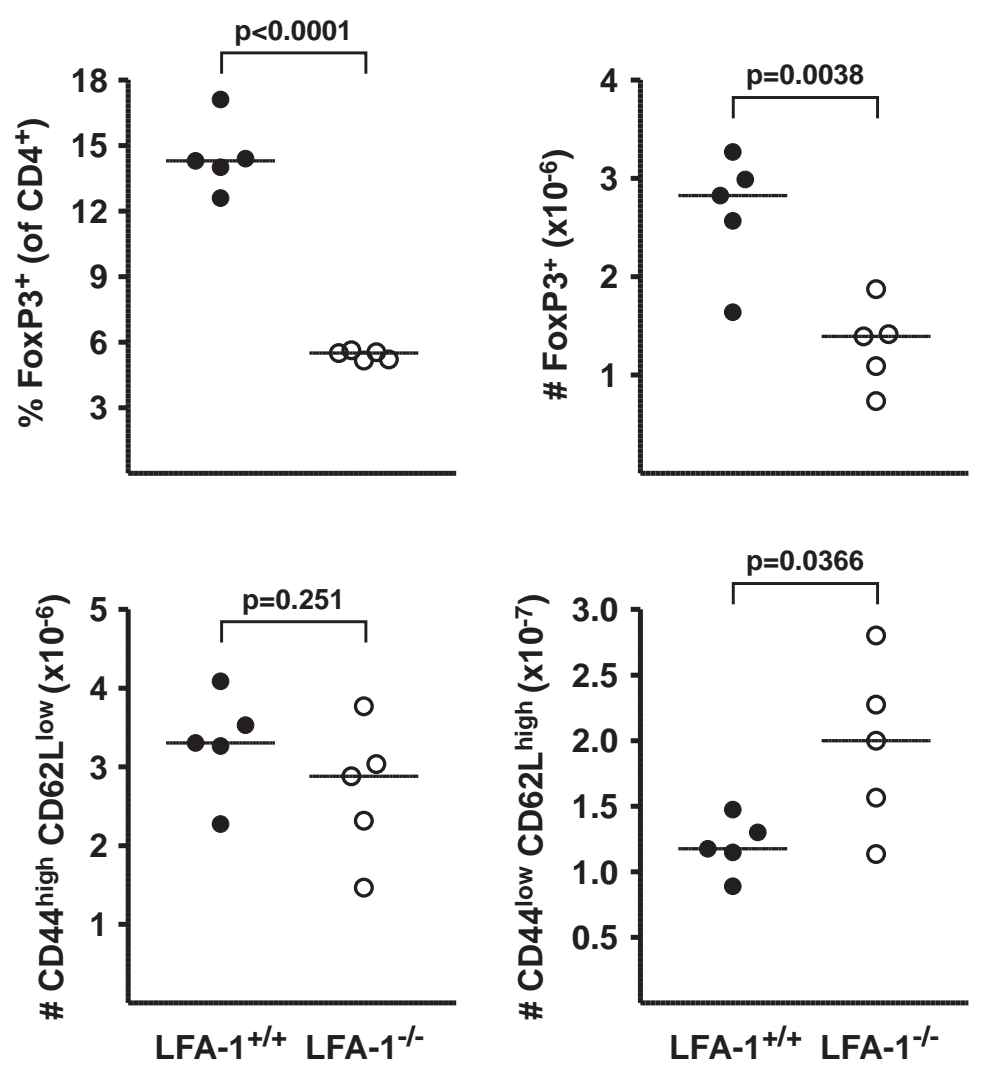

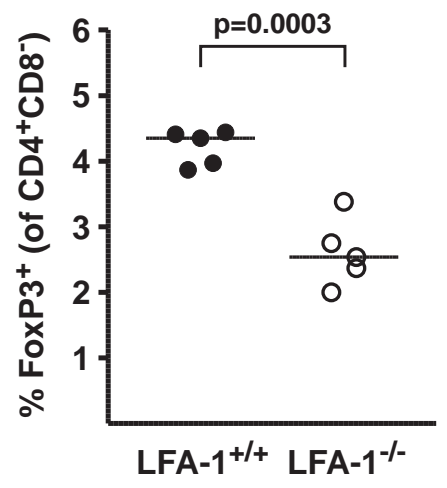

Fig. 6 


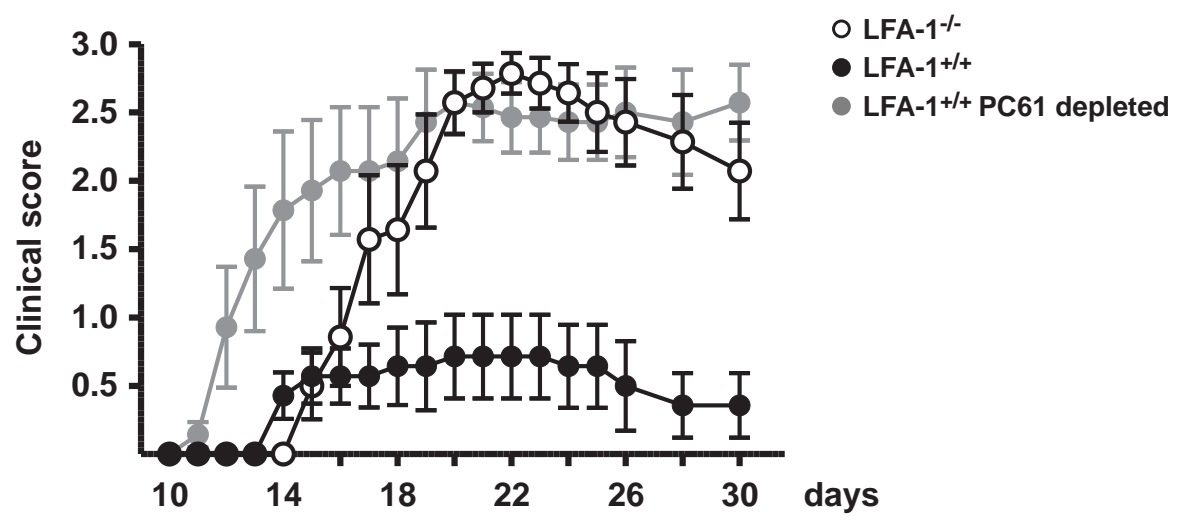

Fig. 7 

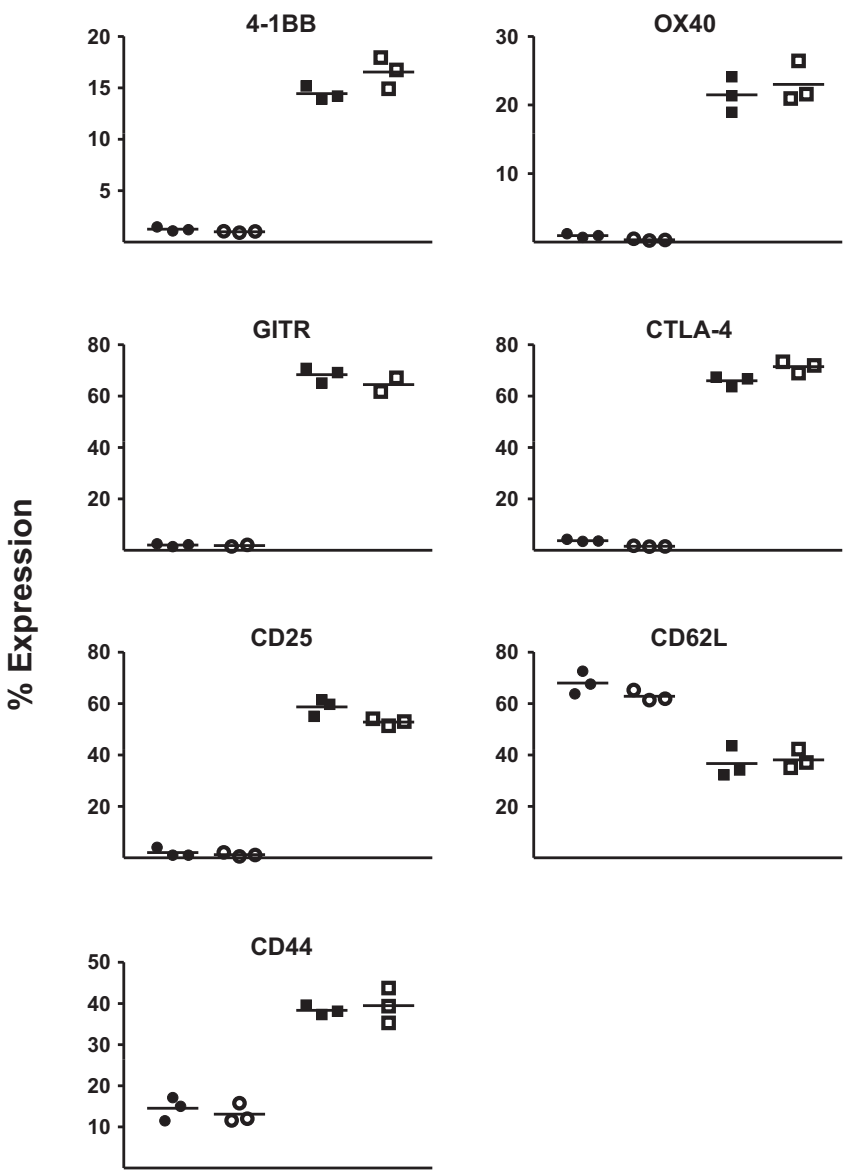

FoxP3 $^{-} \quad$ FoxP3 $^{+}$

Supplementary Figure 1. Characterization of Tregs and nonTregs in WT and LFA-1 KO mice.

Splenocytes from unimmunized LFA-1 $1^{+/+}$(closed symbols) and LFA-1/- mice (open symbols) were stained for CD3, CD4, intracellular FoxP3, and the indicated cell surface markers and analyzed by flow cytometry. Shown is the proportion of marker positive cells on live, $\mathrm{CD}^{+}, \mathrm{CD}^{+}$, FoxP3- vs. FoxP3 ${ }^{+}$cells. 


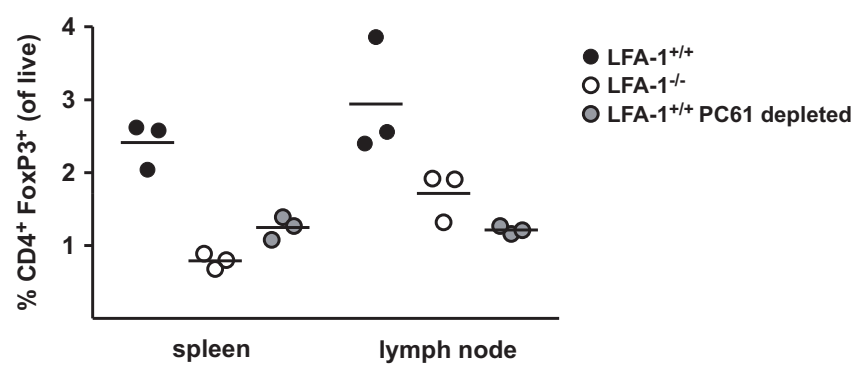

Supplementary Figure 2. Depletion of regulatory T cells.

Tregs were depleted by a single injection of anti-CD25 mAb (clone PC61.5) 8 days before analysis. Spleen and lymph node cells from WT, LFA-1 KO, and PC61-depleted mice were analysed by flow cytometry for FoxP3 positive cells. 